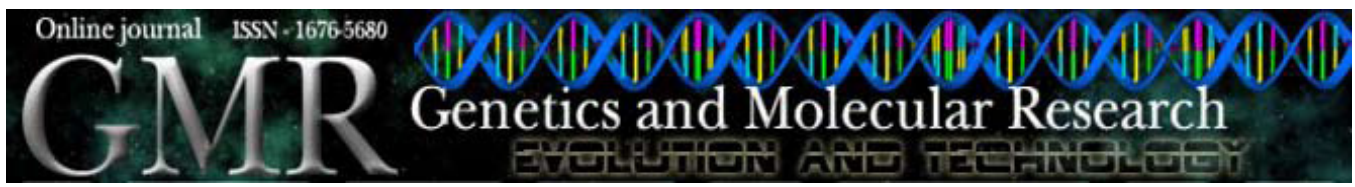

\title{
Lack of association between SNP rs3914132 of the RELN gene and otosclerosis in India
}

\author{
S. Priyadarshi ${ }^{1}$, K.C. Panda ${ }^{2}$, A.K. Panda ${ }^{2}$ and P.V. Ramchander ${ }^{1}$ \\ ${ }^{1}$ Institute of Life Sciences, Nalco Square, Chandrashekarpur, \\ Bhubaneswar, India \\ ${ }^{2}$ Capital Hospital, Unit VI, Bhubaneswar, India \\ Corresponding author: P.V. Ramchander \\ E-mail: pramchander@yahoo.com / ramchanderpv@ils.res.in
}

Genet. Mol. Res. 9 (3): 1914-1920 (2010)

Received May 25, 2010

Accepted July 13, 2010

Published September 28, 2010

DOI 10.4238/vol9-3gmr890

\begin{abstract}
Otosclerosis (MIM 166800) is primarily a metabolic bone disorder of the otic capsule, which leads to bony fixation of the stapedial footplate in the oval window; it is among the most common causes of acquired hearing loss. The etiology of this disease is largely unknown, although epidemiological studies suggest the involvement of both genetic and environmental factors. Recently, a reelin gene, SNP rs3914132, located in intron 2, was shown to be associated with otosclerosis in a European population. When we sequenced blood DNA samples of 85 individuals with otosclerosis and 85 controls, four SNPs of this gene: $r s 3914131(\mathrm{P}=0.6463)$, rs3914132 $(\mathrm{P}=0.1822)$, rs9641319 ( $\mathrm{P}=0.7371)$, and $\operatorname{rs} 10227303(\mathrm{P}=0.5669)$ were not significantly associated with this disease. In one familial case, a novel variant $(\mathrm{C} / \mathrm{T})$ at contig position 2923488 was found to be inherited by the proband and affected family members.
\end{abstract}

Key words: Otosclerosis; Reelin gene; SNP 


\section{INTRODUCTION}

Otosclerosis (OTSC) is a progressive conductive hearing loss caused by excessive bone growth at the stapedial footplate of the middle ear, which interferes with the transmission of sound. Otosclerosis is found to be more frequent in Caucasians and is rare among blacks, Asians and Native Americans (Altmann et al., 1967; Gordon, 1989). It has been classified in two forms, clinical and histological otosclerosis (Schuknecht and Barber, 1985). Clinical otosclerosis has a prevalence of $0.3-0.4 \%$ in the Caucasian population and is twice as frequent in females as in males. Histological otosclerosis is present in 2.5 to $12 \%$ of the Caucasian population without clinical manifestation and can be diagnosed by CT scanning or sectioning of temporal bone at autopsy (Declau et al., 2007). Epidemiological studies have shown the prevalence of histological otosclerosis in Asians and blacks is 5 and $1 \%$, respectively (Guild, 1944; Hueb et al., 1991). Bone remodeling in both clinical and histological otosclerosis is caused by the same or different causes that have yet to be discovered. The typical age of onset varies between 15 and 45 years with the average age of onset falling in the third decade. In $85 \%$ of the patients both ears are involved with hearing impairment. Patients with OTSC can have vertigo and tinnitus as major clinical symptoms (Menger and Tange, 2003).

From the genetic point of view, otosclerosis is considered to be a multifactorial disorder with a rare autosomal dominant inheritance pattern with reduced penetrance. Genetic factors are supported as causal agent after the identification of eight monogenic loci viz: OTSC1 on chromosome 15q25-26, OTSC2 on 7q34-36, OTSC3 on 6p21-22, OTSC4 on 16q21-23.2, OTSC5 on 3q22-24, OTSC7 on 6q13-16.1, and OTSC 8 on 9p13.1-9q21.11. However, none of the causative genes at these loci has been identified (http://hereditaryhearingloss.org/). It has been reported that several genes - BMP2, BMP4, COL1A1, TGFB1, ACE, and AGT showed association with otosclerosis (McKenna et al., 1998; Chen et al., 2007; Thys et al., 2007; Imauchi et al., 2008). However, the evidence of association of COL1A1, ACE and AGT was shown to be conflicting (Rodriguez et al., 2004; Schrauwen et al., 2009b).

Recently, a genome-wide association study reported a novel loci (7q22.1) showing a strong association between intron 1-4 of the RELN gene and found a causative single-nucleotide polymorphism (SNP) rs3914132 for OTSC in intron 2 at contig position 2923439 (Schrauwen et al., 2009a). Reelin is a secreted extracellular matrix glycoprotein that plays an important role in neuronal migration during embryonic development of the brain (Rice and Curran, 2001). It has been demonstrated that reelin protein is up regulated when treated with a chemotherapeutic drug cisplatin, suggesting a prosurvival response in rat hair cells (Jamesdaniel et al., 2008). It is not clear whether the reelin acts as such in the otic capsule of the ear. Although reelin has been shown to be expressed in the human stapedial footplate samples, human inner ear and mouse inner ear, the exact role in pathogenesis of OTSC is not yet known (Schrauwen et al., 2009a).

The present study investigated the association of causative SNP rs3914132 with otosclerosis in an Indian population.

\section{MATERIAL AND METHODS}

\section{Subjects}

Eighty-five non-syndromic otosclerosis cases diagnosed in the ENT Unit of Capital 
Hospital, Bhubaneswar, Orissa, were included in this study. Clinical information regarding the presentation of disease, demography, family history, economic status, and maternal history was recorded for all patients. Clinical diagnosis was based on surgical findings during stapes surgery or audiological-clinical data. The diagnosis of clinical otosclerosis was based on family history, otoscopy, audiometry, and impedance testing. Pure-tone audiometry was carried out in a soundproof room using standard procedures. The frequencies tested for air conduction were 125, 250, 500, 1000, 2000, 4000, and $8000 \mathrm{~Hz}$ and for bone conduction were 250, 500, 1000,2000 , and $4000 \mathrm{~Hz}$. For controls, 85 ethnically, age- and gender-matched individuals without any history of hearing impairment in their family were selected at random. This study was approved by the Institutional Human Ethics Committee.

\section{Genotyping}

Venous blood samples were collected from all cases and controls after obtaining the consent, and genomic DNA was extracted using the rapid non-enzymatic method (Lahiri and Nurnberger Jr., 1991). The amount and purity of the DNA was quantified for each sample by spectrophotometry. For polymerase chain reaction (PCR) amplification and sequencing, the primers REL-F 5'-CAGCCACCACCCTTGAACTCACT-3' and REL-R 5'-TCTCATCCTTGGACAATTCTGGCA-3' were designed from contig position 2923357 to 2923623 of intron-2 of the RELN gene covering the causative SNP rs3914132. PCR was performed with $100 \mathrm{ng}$ genomic DNA in a $50-\mu \mathrm{L}$ reaction, containing $5 \mu \mathrm{L}$ PCR buffer and $1.25 \mathrm{U}$ Taq DNA polymerase, $1.5 \mathrm{mM} \mathrm{MgCl}_{2}, 200 \mu \mathrm{M}$ deoxynucleotide triphosphates (dNTPs), and 20 pmol each of primers. Samples were denatured at $95^{\circ} \mathrm{C}$ for $5 \mathrm{~min}$, followed by 36 cycles of $95^{\circ} \mathrm{C}$ for $30 \mathrm{~s}, 61^{\circ} \mathrm{C}$ for $30 \mathrm{~s}$, and $72^{\circ} \mathrm{C}$ for $30 \mathrm{~s}$ and extended at $72^{\circ} \mathrm{C}$ for $10 \mathrm{~min}$. The amplicons were cleaned using a QIAquick PCR purification kit, according to manufacturer instructions. The products were sequenced using the same primer as above from forward and reverse directions on an ABI 3730 automated sequencer at the Centre for Genomic Application, New Delhi.

\section{Statistical analysis}

We tested all SNPs for deviation from the Hardy-Weinberg equilibrium (HWE) in both cases and controls by using HWE calculator for biallelic markers (www.oege.org/ software/hwe-mr-calc.shtml). None of the SNPs showed deviation from HWE. The association between the presence of SNPs rs3914131, rs3914132, rs9641319, and rs10227303 of RELN with OTSC was evaluated by the Fisher exact test using the Graph pad prism software (version 5.01). Significant differences were considered to be $\mathrm{P}<0.05$. Haplotype analysis was performed using the SNP-Alyze software (version 7.0).

\section{RESULTS}

Audiological characteristics of the 85 cases included in the study are shown in Table 1. The patients' ages at the time of diagnosis ranged from 15 to 70 years; there were 56 $(65.88 \%)$ males and $29(34.12 \%)$ females. Onset of hearing loss was most reported in the age group of 40-50 years. Of the cases collected, the mixed type of hearing loss was found 
to be higher than conductive and sensorineural. In most of the cases, deafness was bilateral with moderate hearing loss (Table 1). Tinnitus was reported in $59(69.41 \%)$ cases.

\begin{tabular}{|c|c|}
\hline Variables studied & No. of patients (\%) \\
\hline \multicolumn{2}{|l|}{ Age (years) } \\
\hline $11-20$ & $5(5.88 \%)$ \\
\hline $21-30$ & $13(15.29 \%)$ \\
\hline $31-40$ & $21(24.71 \%)$ \\
\hline $41-50$ & $18(21.12 \%)$ \\
\hline$>50$ & $28(32.94 \%)$ \\
\hline \multicolumn{2}{|l|}{ Gender variation } \\
\hline Male & $56(65.88 \%)$ \\
\hline Female & $29(34.12 \%)$ \\
\hline \multicolumn{2}{|l|}{ Age of onset of deafness } \\
\hline $11-20$ years & $10(11.76 \%)$ \\
\hline $21-30$ years & $25(29.41 \%)$ \\
\hline $31-40$ years & $18(21.18 \%)$ \\
\hline $40-50$ years & $32(37.65 \%)$ \\
\hline \multicolumn{2}{|l|}{ Types of otosclerosis } \\
\hline Bilateral & $83(97.65 \%)$ \\
\hline Unilateral & $2(2.35 \%)$ \\
\hline \multicolumn{2}{|l|}{ Types of hearing loss } \\
\hline Conductive & $34(40 \%)$ \\
\hline Mixed & $45(52.95 \%)$ \\
\hline Sensorineural & $6(7.05 \%)$ \\
\hline \multicolumn{2}{|l|}{ Severity of hearing loss } \\
\hline Mild (26-40 dB ) & $9(10.59 \%)$ \\
\hline Moderate (41-55 dB ) & $56(65.88 \%)$ \\
\hline Moderately severe $(56-70 \mathrm{~dB})$ & $10(11.77 \%)$ \\
\hline Severe $(71-90 \mathrm{~dB})$ & $6(7.05 \%)$ \\
\hline Profound $(90+)$ & $4(4.71 \%)$ \\
\hline
\end{tabular}

$\mathrm{dB}=$ decibels.

Sequencing of intron 2 of the RELN gene from contig position 2923357 to 2923623 in patients and controls detected four known SNPs: rs3914131 (A/G), rs3914132 (C/T), rs9641319 (T/C), and rs 10227303 (A/T). In one familial case, a novel variant $(\mathrm{C} / \mathrm{T})$ at contig 2923488 was found to be inherited among the affected family members (Table 2).

Table 2. RELN variants in this study (only the frequencies of rare alleles are shown).

\begin{tabular}{lcccc}
\hline SNPs & Position & Sequence change & Frequency in cases & Frequency in controls \\
\hline rs3914131 & 2923396 & $\mathrm{~A} \rightarrow \mathrm{G}$ & $23 / 170(0.14 \%)$ & $27 / 170(0.16 \%)$ \\
rs3914132 & 2923439 & $\mathrm{C} \rightarrow \mathrm{T}$ & $16 / 170(0.09 \%)$ & $25 / 170(0.15 \%)$ \\
rs9641319 & 2923518 & $\mathrm{~T} \rightarrow \mathrm{C}$ & $66 / 170(0.39 \%)$ & $62 / 170(0.36 \%)$ \\
rs10227303 & 2923553 & $\mathrm{~A} \rightarrow \mathrm{T}$ & $17 / 170(0.1 \%)$ & $13 / 170(0.08 \%)$ \\
$* *$ & 2923488 & $\mathrm{C} \rightarrow \mathrm{T}$ & $1 / 170(0.006 \%)$ & 0 \\
\hline
\end{tabular}

**Novel single-nucleotide polymorphism (SNP) identified at contig position 2923488 of intron-2 of the RELN gene. The positions were within reference sequence accession number NT_079596.2 (NCBI).

The minor allele ' $\mathrm{C}$ ' frequency of SNP rs3914132 was found to be 0.09 in cases and 0.15 in controls. For major allele (T), the allele frequency was 0.91 in the patient group and 0.85 in the control group. When allele frequencies were compared between cases and controls, no significant differences were observed either for causative SNP rs3914132 (P = 0.1822 ; odds ratio $(\mathrm{OR})=1.659$; confidence interval at $95 \%(95 \% \mathrm{CI})=0.8514-3.235)$ or 
rs3914131 $(\mathrm{P}=0.6463 ; \mathrm{OR}=0.8287 ; 95 \% \mathrm{CI}=0.4539-1.513)$, rs9641319 $(\mathrm{P}=0.7371 ; \mathrm{OR}$ $=0.9046 ; 95 \% \mathrm{CI}=0.5832-1.403), \mathrm{rs} 10227303(\mathrm{P}=0.5669 ; \mathrm{OR}=0.7452 ; 95 \% \mathrm{CI}=0.3500$ 1.587). The genotype and allele frequencies for the above SNPs are shown in Table 3.

\begin{tabular}{|c|c|c|c|c|c|}
\hline SNP & Genotype allele & Cases $(\mathrm{N}=85)$ & Controls $(\mathrm{N}=85)$ & OR $(95 \% \mathrm{CI})$ & $\mathrm{P}$ \\
\hline \multirow[t]{5}{*}{ rs3914131 } & AA & $3(3.53)$ & $4(4.71)$ & $1.2060(0.6029-2.411)$ & 0.7245 \\
\hline & $\mathrm{AG}$ & $17(20.00)$ & $19(22.35)$ & & \\
\hline & GG & 65 (76.47) & $62(72.94)$ & & \\
\hline & A & 0.14 & 0.16 & $0.8287(0.4539-1.513)$ & 0.6463 \\
\hline & G & 0.86 & 0.84 & & \\
\hline \multirow[t]{5}{*}{ rs3914132 } & $\mathrm{CC}$ & 0 & $3(3.53)$ & $1.5060(0.7264-3.122)$ & 0.3575 \\
\hline & СТ & $16(18.20)$ & $19(22.35)$ & & \\
\hline & TT & $69(81.80)$ & $63(74.12)$ & & \\
\hline & $\mathrm{C}$ & 0.09 & 0.15 & $1.6590(0.8514-3.235)$ & 0.1822 \\
\hline & $\mathrm{T}$ & 0.91 & 0.85 & & \\
\hline \multirow[t]{5}{*}{ rs9641319 } & TT & $33(38.82)$ & $34(40.00)$ & $0.9519(0.5144-1.762)$ & 1 \\
\hline & TC & $38(44.71)$ & $40(47.00)$ & & \\
\hline & $\mathrm{CC}$ & $14(16.47)$ & $11(13.00)$ & & \\
\hline & $\mathrm{T}$ & 0.61 & 0.64 & $0.9046(0.5832-1.403)$ & 0.7371 \\
\hline & $\mathrm{C}$ & 0.39 & 0.36 & & \\
\hline \multirow[t]{5}{*}{ rs 10227303} & AA & $68(80.00)$ & $72(84.70)$ & $0.7222(0.3262-1.587)$ & 0.5467 \\
\hline & АT & $17(20.00)$ & $13(15.30)$ & & \\
\hline & TT & 0 & 0 & & \\
\hline & A & 0.9 & 0.92 & $0.7452(0.3500-1.587)$ & 0.5669 \\
\hline & $\mathrm{T}$ & 0.1 & 0.08 & & \\
\hline
\end{tabular}

$\overline{\mathrm{SNP}}=$ single-nucleotide polymorphism; OR $=$ odd ratio; $95 \% \mathrm{CI}=$ confidence interval at $95 \%$. No significant differences of the genotype and allele distributions were found between cases and controls.

Furthermore, to evaluate the extent of linkage disequilibrium, haplotypes were constructed for four known SNPs using the SNP Alyze software (version 7.0) and five haplotypes were found to be frequent. The haplotype GTTA was found to be the most frequent in both cases $(43.18 \%)$ and controls $(41.18 \%)$ but no significant differences existed between cases and controls (Table 4).

Table 4. Frequency of common haplotypes in otosclerosis disease cases and controls.
\begin{tabular}{lccccc}
\hline Haplotype* & Overall $(\mathrm{N}=170)$ & Cases $(\mathrm{N}=85)$ & Controls $(\mathrm{N}=85)$ & $\chi^{2}$ & Permutated P value \\
\hline GTTA & 0.4169 & 0.4318 & 0.4118 & 0.1388 & 0.727 \\
GTCA & 0.3503 & 0.3418 & 0.3529 & 0.0462 & 0.848 \\
ACTA & 0.1082 & 0.0734 & 0.1411 & 4.0688 & 0.055 \\
GTTT & 0.0796 & 0.0852 & 0.0705 & 0.2559 & 0.638 \\
ATCA & 0.0261 & 0.0405 & 0.0118 & 2.7493 & 0.247 \\
\hline
\end{tabular}

*Haplotype with frequency $<1 \%$ in both groups was not shown in table; permutated P values are based on 1000 permutations.

\section{DISCUSSION}

In the present study, evaluation of epidemiological parameters revealed a female to male ratio of 1:1.97, although previous studies reported that females are twice as frequent as males (Manolidis et al., 2003; Moumoulidis et al., 2007). This may be due to the small sample size included in the study or due to differences in race and incidence of otosclerosis. However, 
histological studies do not confirm the gender ratio difference (Altmann et al., 1967; Hueb et al., 1991). The mean age of onset of hearing loss was found to be 34 years, but a mean of 41 years was reported in a South African population (Tshifularo and Joseph, 2008). However, it is known that the mean age of onset of deafness in OTSC is in the third decade with some cases exceptionally beginning in early childhood or as late as at 60 years (Niedermeyer and Arnold, 2002). Pure tone audiometry shows a high number of patients with mixed hearing loss and conductive hearing loss, which is the characteristic feature of OTSC (Table 1). Positive family history was reported from $49(57.64 \%)$ cases, indicating a genetic basis for the condition and our data are similar to previous reports, which showed that $50-70 \%$ cases of otosclerosis have positive family history (Larsson, 1960; Morrison, 1967). All the multigenerational families collected showed the autosomal dominant mode of inheritance.

Genotyping of cases and controls identified four known SNPs and one novel variant (Table 2). The novel variant $\mathrm{C}$ to $\mathrm{T}$ at contig 2923488 was found to be inherited in all the affected members of a positive family case.

The genotype and allele distributions of the four known SNPs are shown in Table 3. The minor allele (C) frequency for the causative SNP rs3914132 in both patient and control groups was found to be 0.09 and 0.15 . For major allele (T), the allele frequency was 0.91 in the patient group and 0.85 in controls; however, the minor allele frequency for this SNP across the entire Hap Map population was found to be $0.17 \pm 0.01$ (Hap Map draft release No. 1 Phase III). With regard to genotype frequency, 3 controls were found to be homozygous for minor allele $(\mathrm{C})$ while 19 were heterozygous for this variation. None of the cases were found to be homozygous for minor allele (C) but 16 cases have shown heterozygosity for this variation (Table 3). In the Caucasian population, it has been observed that each minor allele (C) at rs3914132 in RELN gene is acting as a protective allele and decreases the risk of otosclerosis by 1.54 times. In the same study, expression of reelin was also detected in human stapedial footplate samples without OTSC (Schrauwen et al., 2009a). The exact role of RELN in the bone remodeling of the otic capsule is not yet known. Recently, it has been shown that reelin expression was found to be up-regulated in the cochlea of rat when treated with the chemotherapeutic drug cisplatin, suggesting a prosurvival response in hair cells (Ohkubo et al., 2007; Jamesdaniel et al., 2008). Whether reelin acts similarly in the otic capsule is unknown. However, we could not demonstrate any significant association of OTSC with the reported causative SNP when the allele frequencies between cases and controls were compared. Similarly, when frequency distributions of alleles and genotypes for the SNPs rs3914131, rs9641319 and rs 10227303 were compared, we did not find any significant association between cases and controls (Table 3). The clinical significance of these SNPs for any disease is not known, so the comparison of allele and genotype frequencies with other ethnic groups was impossible because no such studies exist. We also identified a new variation C to T at contig 2923488 inherited in all the affected members of a positive family case. However, the functional role of this nucleotide substitution remains to be determined.

In an effort to test the association between a set of SNPs and disease status, haplotypes were constructed for all the four known SNPs but none of the permuted P values for any of the haplotypes showed a significant association between cases and controls (Table 4). The novel SNP was excluded from haplotype analysis because of its low frequency in the present study.

The results obtained in the present study suggest that the SNP rs3914132 in the RELN gene is not a significant risk factor for the development of otosclerosis in the Indian popula- 
tion. This may be due to ethnic variation or the small sample size, resulting in low statistical power in the study that was unable to identify the effect of this SNP on otosclerosis.

\section{ACKNOWLEDGMENTS}

We thank all subjects who participated in the present project. Research supported by the Department of Biotechnology, New Delhi, Government of India (Grant Sanction \#BT/ PR8137/GBD/27/14/2006 dated 25.04.2007).

\section{REFERENCES}

Altmann F, Glasgold A and Macduff JP (1967). The incidence of otosclerosis as related to race and sex. Ann. Otol. Rhinol. Laryngol. 76: 377-392.

Chen W, Meyer NC, McKenna MJ, Pfister M, et al. (2007). Single-nucleotide polymorphisms in the COL1A1 regulatory regions are associated with otosclerosis. Clin. Genet. 71: 406-414.

Declau F, van Spaendonck M, Timmermans JP, Michaels L, et al. (2007). Prevalence of histologic otosclerosis: an unbiased temporal bone study in Caucasians. Adv. Otorhinolaryngol. 65: 6-16.

Gordon MA (1989). The genetics of otosclerosis: a review. Am. J. Otol. 10: 426-438.

Guild SR (1944). Histologic otosclerosis. Ann. Otol. Rhinol. Laryngol. 53: 246-266.

Hueb MM, Goycoolea MV, Paparella MM and Oliveira JA (1991). Otosclerosis: the University of Minnesota temporal bone collection. Otolaryngol. Head Neck Surg. 105: 396-405.

Imauchi Y, Jeunemaitre X, Boussion M, Ferrary E, et al. (2008). Relation between renin-angiotensin-aldosterone system and otosclerosis: a genetic association and in vitro study. Otol. Neurotol. 29: 295-301.

Jamesdaniel S, Ding D, Kermany MH, Davidson BA, et al. (2008). Proteomic analysis of the balance between survival and cell death responses in cisplatin-mediated ototoxicity. J. Proteome. Res. 7: 3516-3524.

Lahiri DK and Nurnberger JI Jr (1991). A rapid non-enzymatic method for the preparation of HMW DNA from blood for RFLP studies. Nucleic Acids Res. 19: 5444.

Larsson A (1960). Otosclerosis, a genetic and clinical study. Acta Otolaryngol. Suppl. 154: 1-86.

Manolidis S, Alford RL, Smith RJ, Ball C, et al. (2003). Do the genes that cause otosclerosis reduce susceptibility to otitis media? Otol. Neurotol. 24: 868-871.

McKenna MJ, Kristiansen AG, Bartley ML, Rogus JJ, et al. (1998). Association of COL1A1 and otosclerosis: evidence for a shared genetic etiology with mild osteogenesis imperfecta. Am. J. Otol. 19: 604-610.

Menger DJ and Tange RA (2003). The aetiology of otosclerosis: a review of the literature. Clin. Otolaryngol. Allied Sci. 28: $112-120$.

Morrison AW (1967). Genetic factors in otosclerosis. Ann. R. Coll. Surg. Engl. 41: 202-237.

Moumoulidis I, Axon P, Baguley D and Reid E (2007). A review on the genetics of otosclerosis. Clin. Otolaryngol. 32: 239-247.

Niedermeyer HP and Arnold W (2002). Etiopathogenesis of otosclerosis. ORL J. Otorhinolaryngol. Relat. Spec. 64: 114-119.

Ohkubo N, Vitek MP, Morishima A, Suzuki Y, et al. (2007). Reelin signals survival through Src-family kinases that inactivate BAD activity. J. Neurochem. 103: 820-830.

Rice DS and Curran T (2001). Role of the reelin signaling pathway in central nervous system development. Anпи. Rev. Neurosci. 24: 1005-1039.

Rodriguez L, Rodriguez S, Hermida J, Frade C, et al. (2004). Proposed association between the COL1A1 and COL1A2 genes and otosclerosis is not supported by a case-control study in Spain. Am. J. Med. Genet. A 128A: 19-22.

Schrauwen I, Ealy M, Huentelman MJ, Thys M, et al. (2009a). A genome-wide analysis identifies genetic variants in the RELN gene associated with otosclerosis. Am. J. Hum. Genet. 84: 328-338.

Schrauwen I, Thys M, Vanderstraeten K, Fransen E, et al. (2009b). No evidence for association between the reninangiotensin-aldosterone system and otosclerosis in a large Belgian-Dutch population. Otol. Neurotol. 30: 1079-1083.

Schuknecht HF and Barber W (1985). Histologic variants in otosclerosis. Laryngoscope 95: 1307-1317.

Thys M, Schrauwen I, Vanderstraeten K, Janssens K, et al. (2007). The coding polymorphism T263I in TGF-beta1 is associated with otosclerosis in two independent populations. Hum. Mol. Genet. 16: 2021-2030.

Tshifularo M and Joseph CA (2008). Otosclerosis and TGF-beta 1 gene in black South Africans. S. Afr. Med. J. $98: 720$ 723. 